\title{
Regionalización, Comunidades Campesinas y Desarrollo
}

\author{
José Vegas Pozo \\ E-mail: thania699@hotmail.com \\ Departamento de Antropología, UNMSM
}

\begin{abstract}
Resumen
En este trabajo se analizan algunos problemas estructurales de la sociedad peruana contemporánea como la regionalización. Comunidades Campesinas y Desarrollo y el proceso de constitución transversal de las regiones.
\end{abstract}

Palabras clave: Regionalización, comunidades campesinas y desarrollo.

\begin{abstract}
In my work analize some structural problems of the contemporanean Peruvian Society like the Regionalization, rural communities and unrolling.
\end{abstract}

Key words: Regionalización, comunidades campesinas y desarrollo.

Mi trabajo se propone explorar los problemas de descentralización y regionalización de nuestra sociedad y su implicancia en el desarrollo. La necesidad de la descentralización económica, política y administrativa para dar paso a una Nueva Sociedad que elimine la marginación, discriminación y exclusión económica y política de la mayoría de la población urbana popular andina y amazónica y permita la redistribución de los recursos y su participación en las distintas instancias del poder político, a nivel local, regional y nacional. Democratizar e institucionalizar realmente nuestro escenario social.

La implementación de una macrorregionalización transversal que apertura una perspectiva de desarrollo del conjunto de la economía, del mercado interno, que limite la extrema desigualdad socioeconómica existente, acumulada en las últimas décadas como expresión de la "herencia colonial", y por la inexistencia de una clase social burguesa orgánica y dirigente con un proyecto de desarrollo nacional Integral de largo plazo, que reconstruya la nación.

Considero que estos problemas son de naturaleza estructural porque socavan las bases del sistema económico social existente que no tiene un horizonte claro sino nebuloso y crítico. Más aún, agudizado por la recesión económica capitalista mundial iniciada en el 2008. 
Sin embargo, es necesario precisar que estos problemas no son de ayer, sino que tienen plena vigencia en la agenda de emergencia política y social. Así, por ejemplo, el analista político Julio Cotler en su clásico texto: Clases, Estado y Nación en el Perú, en el prefacio a la tercera edición - 2005, 25 años después, en su análisis crítico del denominado Gobierno Revolucionario de la Fuerza Armada 1968-1980 afirma: “en resumen, a pesar de las transformaciones que decretó, el gobierno militar fracasó en su proyecto de integración nacional debido a que siguió los tradicionales patrones de comportamiento político autoritario. La pretensión de decretar una revolución "desde arriba", sin tomar en cuenta los intereses sociales y los canales de participación y representación democrática, ocasionó que persistiera la distribución regresiva de los recursos públicos y que los fortalecidos actores sociales desbordaran los restrictivos marcos establecidos por el gobierno revolucionario de la fuerza armada".

Destaco el fracaso del proyecto del Gobierno de la Fuerza Armada por continuar con los tradicionales patrones de comportamiento político autoritario, que históricamente oscilan entre la dictadura y la democracia, es decir, como señalo líneas arriba este autoritarismo transgrede la necesidad de democratizar e institucionalizar realmente el poder político y la participación directa de lo que en mi caracterización denomino sectores urbano populares, andinos y amazónicos. Democratización que es fundamental para la configuración de una nueva sociedad y nación. También considero contraproducente no tomar en cuenta los intereses sociales de los diferentes grupos y clases porque genera una distribución no equitativa de los recursos e ingresos del Estado y afecta la gobernabilidad del país y frustra las expectativas ciudadanas. No olvidemos que el desarrollo social está en relación directa con dos de los factores endógenos más importantes: con el desarrollo de su capacidad productiva y con la innovación de sus formas de distribución de la riqueza social.

En efecto, los militares se propusieron realizar un conjunto de reformas sociales, económicas y políticas y terminar con "las estructuras tradicionales", causa del atraso y dependencia de nuestra economía y lograr la integración nacional, a diferencia de la realidad de la mayoría de los países de América Latina. Pero como he señalado, y sobre todo los estudiosos de ese período, el proyecto fracasó.

Lógicamente, el experimento peruano es mucho más complejo, denso y tiene muchas aristas tanto a nivel interno como a nivel de los organismos multilaterales: BM, BID, OMC.

José Matos en su libro Desborde popular y crisis del Estado, veinte años después. La Nueva Lima. 2004, reflexiona sobre un conjunto de intensos cambios económicos, sociales y culturales que se producen a partir de 1950, como consecuencia de la masiva migración andina del campo a la ciudad, por la crisis agraria y en busca de mejores oportunidades laborales y económicas. Su meta se concentra en la macrocefalia de Lima por la concentración del poder político, social y económico en la capital, que es el principal obstáculo histórico-estructural que enfrenta el Perú porque no genera el desarrollo del conjunto del país y que produce el desborde popular y la crisis del Estado. De allí, la necesidad de la descentralización y la conformación de macrorregiones.

Con su relectura, también reflexiono y concuerdo con la profundidad del análisis del conjunto de procesos y transformación que se realizan en la totalidad del país a partir de 1950. Transformaciones que cambian el rostro de la ciudad, principalmente de la megalópolis Lima en las primeras décadas y posteriormente las ciudades medias. Se produce la ruralización de las ciudades, la formación de barriadas por los migrantes.

A esta ruralización de las ciudades se agregan, la urbanización general, la semiindustrialización propia de una economía dependiente. Relievo del texto, la propuesta de la institucionalidad, descentralización, democratización y la creación de una auténtica 
sociedad nacional. Propuesta que ratifica mi alternativa de elaborar y realizar un Proyecto de Desarrollo Nacional Integral que reconstruya la Nación.

Mi trabajo explora si entre los actores sociales y políticos existe un campo básico de coincidencias respecto de los términos estructurales y políticos, en que se plantean los problemas regionalización, comunidades campesinas y su desarrollo socioeconómico.

Para el análisis de los principales aspectos del problema económico regional, sobre cuyas bases se sustenta la estructura política del Estado, utilizaré, en parte, al mejor investigador sobre la temática, Gonzales de Olarte, que en uno de sus escritos sostiene:

"El problema económico desde el punto de vista regional se puede sintetizar en tres puntos: El primero es de la centralización, concentración y aglomeración económica, que a menudo se confunde con el problema del centralismo. El segundo alude a las desigualdades regionales en recursos, procesos o modos de producción, ingresos y bienestar. En tercer lugar se ubica un tema que recién comienza a ser tratado con cierta acuciosidad: el carácter entrípeto del crecimiento regional en el Perú". ${ }^{1}$

La centralización, concentración y aglomeración son conceptos más precisos que el descentralismo que tiene una connotación política. Según las fuentes estadísticas, en Lima se concentra un promedio del $60 \%$ de la industria, del sector financiero, comercial, aglomeración urbana y de población y Centros de Educación Superior.

Esta es la realidad, después de varios procesos de descentralización anteriores, que no favorecen el desarrollo regional provinciano y acarrean graves consecuencias de desempleo, educación, salud y pobreza.

Además, es correcto señalar que todo proceso de centralización, concentración, aglomeración de recursos, capital y población, crea economías de escala, economías externas y de aglomeración, que sólo aparecen cuando hay una gran masa de capital, personas e industrias. Precisamos también que esos procesos de concentración se realizan dentro y fuera de la región de Lima.

Además, el problema económico regional genera la desigualdad, inter e intra, es decir, tanto entre regiones como dentro de cada una de ellas. Empírica y sensorialmente la desigualdad más visible es la que se da entre las regiones de desarrollo capitalista y aquellos espacios mercantiles no capitalistas como el de los campesinos andinos y minifundistas en general. La segunda desigualdad notoria es la que existe dentro de cada región entre el campo y la ciudad. De ahí que varios investigadores señalen que el Perú es un país dividido en dos: El Perú oficial occidentalizado y dependiente y el Perú profundo, de los de abajo, los marginados.

La tercera desigualdad gira en torno al bienestar en materia de educación, salud, cultura. En realidad, nos referimos a las Programas Sociales del Estado en el suministro de servicios sociales y que alude al problema político de cómo, por qué y para quién gasta el Estado. He planteado en otros trabajos:

“...ya que no contamos con una clase burguesa dirigente, hegemónica, sino con fracciones de clases con intereses políticos y de defensa de sus intereses económicos quienes asumen la conducción del cambio social y postulen como meta estratégica la construcción de una Nueva Sociedad, sean los sectores marginados urbanos y rurales, el proletariado y el campesinado y también es imprescindible cambiar la estructura del Estado para que asuma la defensa de estos sectores y su desarrollo a nivel nacional". ${ }^{2}$

1 Gonzáles de Olarte, Efraín. Economía para la democracia. IEP. 1989.

Pulgar Vidal, Javier. "La regionalización transversal del territorio peruano con el fin de lograr la administración del territorio nacional”. En: Lecturas sobre regionalización. Universidad del Pacifico, 1981

2 Vegas Pozo, José. "A propósito del desarrollo del capitalismo en las comunidades campesinas de Canta: Alcances y límites”. En Revista de Antropología. Año I, № 1. UNMSM. Mayo 2003. 
El carácter centrípeto del crecimiento regional se caracteriza por un dinamismo económico divergente en términos del desarrollo regional desigual y dependiente. En este sentido, Lima y la costa crecen en función de la economía externa y el resto de regiones no necesariamente tienen dinámicas independientes porque hay una débil relación de intercambio de insumos entre el resto de regiones y Lima, pues ésta está más relacionada con el mercado exterior. Además, el resto de regiones está fuertemente articulada a través de la demanda final de bienes industriales y en oferta de alimentos a Lima y está supeditada a los términos de intercambio con ella.

Lo anterior se explica porque no hay eslabonamientos productivos con las regiones, lo que implica que cuando aumenta la producción en Lima, no hay necesariamente un aumento en la demanda de materias primas que podrían suministrar los campesinos agricultores o mineros. Además, entre campo y ciudad, dentro de cada región y a nivel nacional existe un creciente divorcio entre la producción y el consumo, lo cual es grave. Esto porque las regiones fuera de Lima consumen relativamente menos de lo que producen sus entornos rurales, en consecuencia las ciudades no arrastran al campo y éste tiende a estancarse. También es necesario señalar que la razón de este fenómeno se encuentra en las políticas estatales de importación, pues es más fácil importar que desarrollar la producción agropecuaria que constituye la base de todo proceso de desarrollo industrial nacional.

Aquí aparecen, pues, las vinculaciones entre el sistema político y el económico en lo referente a la relación producción-consumo.

En suma el sistema político favorece a la población urbana y esto significa menores ingresos para el resto de regiones y para el campo y su desarrollo. Es necesario destacar la heterogeneidad productiva de nuestra economía con sectores con otra racionalidad y articulada contradictoriamente a la economía nacional y el hecho de que estos sectores son sólo relativamente funcionales al sistema porque la riqueza urbana no se debe al empobrecimiento campesino, sino al revés. En el desarrollo capitalista peruana, si bien es cierto existe una significativa diferenciación campesina que se expresa a nivel de la estructura social en la existencia de apus y huacchas no se ha producido un proceso de descampesinización y proletarización de las áreas campesinas, sino que se hallan económicamente marginadas y estancadas.

En ese sentido, el aspecto político más importante del problema regional es el centralismo, tanto como tema de decisiones como ejecución de las mismas. Aquí surge el carácter y estructura del Estado que se ha ido constituyendo en un poder en sí, y es probablemente el poder más centralista que existe. Esto es lo más visible del centralismo. Pero lo que es necesario conocer es quiénes toman las decisiones y por qué. Como la toma de decisiones está muy ligado al patrón de crecimiento económico primario exportador, el centralismo tiende a favorecer a la economía urbana limeña y costeña. Las políticas macroeconómicas del Estado no han podido corregir las tendencias del patrón de crecimiento en el Perú durante las últimas décadas debido a su carácter coyuntural.

El crecimiento desequilibrado entre regiones y sectores productivos es el resultado del patrón de crecimiento basado en las exportaciones primarias y en la semi-industrialización dependiente, que ha privilegiado a la costa y a la selva y ha marginado a la sierra rural y a sus comunidades campesinas, principalmente a la economía andina y amazónica. Es necesario que la regionalización, como medidas para democratizar el desarrollo nacional. 


\section{Características de la pequeña producción campesina}

La unidad de producción campesina se basa en el trabajo familiar con acceso directo a la tierra que trabaja y donde esa tierra que trabaja y el trabajo familiar son los recursos esenciales usados en el proceso productivo.

Las familias campesinas son las unidades de producción y de consumo y sus economías se orientan fundamentalmente a la producción de valores de uso, y secundariamente valores de cambio. Sin embargo, las familias campesinas no son unidades aisladas, sino productores interdependientes cuyos flujos de fuerza de trabajo, cooperación en la producción y el intercambio, son esenciales para sus actividades agropecuarias.

La producción en las unidades agrícolas campesinas tiene por objeto la reproducción de la unidad familiar y no la maximización de la tasa de ganancia capitalista. Busca, pues, garantizar la reproducción de la unidad familiar.

Esta característica de la pequeña producción campesina, resultado de las condiciones históricas dentro de las cuales se desarrolla, permite percibir porqué las unidades campesinas pueden entregar en forma permanente parte del trabajo excedente sin desintegrarse. A diferencia de las unidades capitalistas, en la economía campesina pequeño productora no hay capital que pueda moverse libremente, sino un conjunto de elementos de trabajo y una parcela de tierra, cuyo valor reside casi exclusivamente en su capacidad de darle un fin productivo a la fuerza de trabajo de que dispone la unidad familiar. Pero la diferencia más importante es que en esta unidad se reúne al mismo tiempo la producción y el consumo familiar $y$, por consiguiente la misma no puede desaparecer sin afectar seriamente a todos los integrantes de la familia campesina.

Las unidades económicas campesinas emplean fundamentalmente la fuerza de trabajo familiar, y sólo eventualmente fuerza de trabajo asalariado, todo depende del grado de intensidad de la relación mercancía-dinero y de su inserción en los mercados de productos, trabajo y financiero.

La economía campesina pequeño productora y su núcleo familiar se sustenta en un sistema de multiactividad agropecuarias y extra agropecuarias, a fin de procurarse mayores ingresos y poder sobrevivir en su difícil medio ecológico y social y lograr su desarrollo socioeconómico.

Cuando la producción agrícola de la unidad campesina no asegura su reproducción, el campesinado vende su fuerza de trabajo. Igualmente sucede en las comunidades campesinas andinas donde predomina la actividad ganadera. La autoexplotación de la fuerza de trabajo familiar y la venta de su fuerza de trabajo fuera de su parcela son formas de su estrategia familiar de sobrevivencia en enfrentamiento con el capitalismo y la resistencia que opone el propio campesino a su desaparición.

Los campesinos están incorporados a los mercados feriales locales o regionales, en mayor o menor grado, y la producción de las unidades campesinas generalmente tiene un carácter mercantil. Los campesinos son productores directos que tienen por base la producción mercantil, o semimercantil, según sea el grado de su vinculación y participación en la economía mercantil y capitalista. Esto varía de región a región teniendo en cuenta la heterogeneidad estructural del desarrollo capitalista.

La economía campesina pequeño productora es una forma de producción subordinada que coexiste al interior de diferentes sistemas económico sociales y su carácter dinámico, y los procesos sociales de desarrollo que en ella operan, dependen de las características y dinámica de la sociedad global.

La pequeña producción campesina es uno de los elementos constitutivos, pero no dominante, de la estructura agraria actual, cuyo representante peculiar en el Perú es 
la economía familiar comunera organizada en comunidades campesinas, asentadas mayoritariamente en la región de la sierra. Se expresa fundamentalmente en la existencia de campesinos parcelarios independientes o minifundistas, o sea, las economías con predominio de parcelas individuales y en los campesinos parcelarios comuneros, en las áreas de comunidades campesinas. Estas formas de economía parcelaria coexisten y se entrecruzan, en forma subordinada al interior de la formación social peruana, en el contexto del desarrollo capitalista semicolonial.

\section{Conclusiones}

1. Los integrantes de las comunidades campesinas de Canta toman conciencia de las limitaciones de la regionalización actual.

2. Los comuneros exigen al Gobierno Central los recursos económicos y técnicos para elevar el nivel de la producción y productividad agrícola y pecuaria.

3. Falta coordinación entre la Municipalidad y la Junta de Comunidades para planificar su desarrollo socioeconómico microrregional.

4. La Comunidad sufre un proceso de descomposición interna, con las particularidades de la trama de relaciones ecológicas, económicas y sociales y de acumulación de bienes y recursos que genera la diferenciación social.

5. La economía campesina pequeño productora, agrícola-pastoril, constituye la unidad de producción basada en el trabajo familiar con acceso directo a la tierra que trabaja y donde esa tierra y el trabajo familiar son los recursos esenciales utilizados en el proceso productivo para su desarrollo socioeconómico.

6. El aporte principal del trabajo de investigación es la comprensión de los comuneros de la necesidad de una real regionalización de mediado y largo plazo, como parte de un Proyecto Nacional de Desarrollo, como señalo en mi hipótesis de

\section{Bibliografía}

BASADRE, Jorge y MACERA, Pablo

1984 Conversaciones. Mosca Azul Editores.

BRIGNOL, Raúl y Crispi, J.

1984 El campesinado en América Latina. Una aproximación teórica. CEPAL.

CLEAVES y otros.

1985 El gobierno militar. Una experiencia peruana 1968-1980. IEP.

COTLER, Julio

1994 Política y sociedad en el Perú, cambios y continuidades. IEP. (2005) Clases, Estado y nación en el Perú. Prefacio a la tercera edición. IEP.

DOLLFUS, Olivier

1981 El reto del espacio andino. IEP.

DURAN, Francisco.

1982 La década frustrada. Los industriales y el poder. 1970 - 1980. DESCO.

FIGUEROA, Adolfo

1986 Desarrollo agrario de la sierra. PUCP.

GONZÁLES DE OLARTE, Efraín

1989 Economía para la democracia. IEP.

1982 Economías regionales del Perú. IEP.

1992 La economía regional de Lima. Crecimiento, urbanización y clases populares. IEP. 
1994 En las fronteras del mercado. Economía política del campesinado en el Perú. IEP, Lima.

KAY, Cristóbal.

1994 El desarrollo excluyente y desigual en la América Latina rural. Atlanta. Georgia.

MANRIQUE, Nelson

1987 Mercado interno y región. La sierra central 1820-1930. DESCO.

MATOS MAR, José

2004 El desborde popular y crisis del Estado. Veinte años después. Segunda Parte. La Nueva Lima. Fondo Editorial del Congreso.

MURMIS, Miguel

1984 Incluidos y excluidos en la reestructuración del agrolatinoamericano. CEPES, Lima.

MURRA, John V.

2002 El mundo andino. Población, medio ambiente y economía. IEP, Lima.

ORTEGA, Emilio

1982 La agricultura campesina en América Latina. Revista CEPAL.

PULGAR VIDAL, Javier

1981 "La regionalización transversal del territorio peruano con el fin de lograr la administración del territorio nacional”. En: Lecturas sobre regionalización. Universidad del Pacífico.

QUIJANO, Aníbal

2000 "Colonialidad del saber, eurocentrismo y América Latina”. Compilador - Lander. FLACSO - UNESCO.

VEGAS POZO, José

2003 "A propósito del desarrollo del capitalismo en las comunidades campesinas de Canta". Revista de Antropología. Cuarta época. Año 1, No 1. UNMSM, Lima.

2007 “Comprensión y explicación en Antropología”. Revista de Antropología. Quinta época $\mathrm{N}^{\mathrm{o}}$ 5. UNMSM, Lima.

ZAVALA, Andrés

2006 La descentralización en el desarrollo económico del Perú. En: Revista Pensamiento Crítico. Revista del Instituto de Investigaciones económicas. UNMSM, Lima. 